\title{
Antidiabetic drug metformin inhibits esophageal adenocarcinoma cell proliferation in vitro and in vivo
}

\author{
SHINTARO FUJIHARA ${ }^{1}$, KIYOHITO KATO ${ }^{1}$, ASAHIRO MORISHITA ${ }^{1}$, HISAKAZU IWAMA ${ }^{2}$, \\ TOMOKO NISHIOKA $^{1}$, TAIGA CHIYO ${ }^{1}$, NORIKO NISHIYAMA ${ }^{1}$, HISAAKI MIYOSHI ${ }^{1}$, \\ MITSUYOSHI KOBAYASHI ${ }^{1}$, HIDEKI KOBARA ${ }^{1}$, HIROHITO MORI ${ }^{1}$, \\ KEIICHI OKANO ${ }^{3}$, YASUYUKI SUZUKI ${ }^{3}$ and TSUTOMU MASAKI ${ }^{1}$ \\ ${ }^{1}$ Department of Gastroenterology and Neurology, ${ }^{2}$ Life Science Resarch Center, and ${ }^{3}$ Gastroenterological Surgery, \\ Faculty of Medicine, Kagawa University, Miki-cho, Kita-gun, Kagawa 761-0793, Japan
}

Received December 16, 2014; Accepted February 2, 2015

DOI: 10.3892/ijo.2015.2903

\begin{abstract}
Esophageal carcinoma is the eighth most common cancer worldwide and the sixth leading cause of cancer-related deaths, with one of the worst prognoses of any form of cancer. Treatment with the anti-diabetic drug metformin has been associated with reduced cancer incidence in patients with type 2 diabetes. This study therefore evaluated the effects of metformin on the proliferation, in vitro and in vivo, of human esophageal adenocarcinoma cells, as well as the microRNAs associated with the antitumor effects of metformin. Metformin inhibited the proliferation of the esophageal adenocarcinoma cell lines OE19, OE33, SK-GT4 and OACM 5.1C, blocking the G0 to G1 transition in the cell cycle. This was accompanied by strong reductions in G1 cyclins, especially cyclin D1, cyclin-dependent kinase (Cdk)4, and Cdk6, and decreases in retinoblastoma protein phosphorylation. In addition, metformin reduced the phosphorylation of epidermal growth factor receptor and insulin-like growth factor and insulin-like growth factor-1 receptor, as well as angiogenesis-related proteins, such as vascular endothelial growth factor, tissue inhibitor of metalloproteinases (TIMP)-1, and TIMP-2. Metformin also markedly altered microRNA expression. Treatment with metformin of athymic nude mice bearing xenograft tumors reduced tumor proliferation. These findings suggest that metformin may have clinical use in the treatment of esophageal adenocarcinoma.
\end{abstract}

\section{Introduction}

Esophageal carcinoma is the eighth most common cancer worldwide and the sixth leading cause of cancer-related

Correspondence to: Professor Tsutomu Masaki, Department of Gastroenterology and Neurology, Kagawa University Faculty of Medicine/Graduate School of Medicine, 1750-1 Ikenobe, Miki-cho, Kita-gun, Kagawa 761-0793, Japan

E-mail: tmasaki@med.kagawa-u.ac.jp

Key words: esophageal adenocarcinoma, metformin, cell cycle, microRNAs, cyclin D1, epidermal growth factor receptor, angiogenesis deaths (1). It has one of the worst prognoses of any cancer, with a 5-year overall survival rate of about $15-25 \%$. Poor prognosis has been associated with diagnosis at advanced (metastatic) stages and its propensity for metastasis $(2,3)$. Esophageal adenocarcinoma is less common than squamous cell carcinoma, although the frequency of adenocarcinoma of the esophagus, esophageal junction (EGJ) and gastric cardia has increased dramatically in Western countries (4).

Metformin is an oral biguanide drug used to treat type 2 diabetes (5). It lowers hyperglycemia by inhibiting hepatic glucose production. A recent epidemiologic survey found that metformin use was associated with reduced cancer incidence in patients with type 2 diabetes $(6,7)$.

The anticarcinogenic activity of metformin has been attributed to several mechanisms, including activation of the LKB1/AMPK pathway, induction of cell cycle arrest and/or apoptosis, inhibition of protein synthesis, inhibition of the unfolded protein response, activation of the immune system, and possible eradication of cancer stem cells (8). Activation of the LKB1/AMPK pathway inhibits mammalian target of rapamycin (mTOR), which negatively affects protein synthesis in cancer cells (8). Metformin has been shown to inhibit the proliferation of various cancer cell types, such as those of prostate (5), breast (9) and colon (10) cancer.

Several in vitro and in vivo studies have also indicated that metformin inhibits the growth of gastric (11), esophageal squamous cell (12), and hepatocellular (13) carcinoma cells. Less is known, however, about the antitumor effects of metformin on esophageal adenocarcinoma cells and on micro RNAs (miRNA) associated with these effects. This study therefore evaluated the effects of metformin on the growth of esophageal adenocarcinoma cell lines, its mechanism of action, and the miRNAs associated with the antitumor effect of metformin.

\section{Materials and methods}

Regents and antibodies. Metformin (1,1-dimethylbiguanide monohydrochloride) was purchased from Astellas Pharma, Inc. Cell counting kit (CCK)-8 was purchased from Dojindo Laboratories (Kumamoto, Japan), and all other chemicals were obtained from Sigma Chemical (Tokyo, Japan). 
Primary antibodies included anti- $\beta$-actin monoclonal antibody (Sigma-Aldrich, St. Louis, MO, USA; A5441, 1:3,000), anti-cyclin D1 (RB-9041, used at 1:1,000; Thermo Fisher Scientific, Walthman, MA, USA), anti-cyclin E (used at 1:1,000; Thermo Fisher Scientific), anti-Cdk6 (sc-177, used at 1:1,000, Santa Cruz Biotechnology, Santa Cruz, CA, USA), anti-Cdk4 (sc-749, used at 1:1,000; Santa Cruz Biotechnology), anti-Cdk2 (sc-163, used at 1:2,000; Santa Cruz Biotechnology), and phosphorylated retinoblastoma protein $(\mathrm{Rb}$; no. 558385 , used at 1:1,000; BD Pharmingen), and anti-Rb (sc-50, used at 1:1,000; Santa Cruz Biotechnology). Secondary antibodies included horseradish peroxidase (HRP)-linked antimouse and antirabbit IgG antibodies (used at 1:2,000; GE Healthcare, UK).

Cell culture and cell proliferation assay. The four human esophageal adenocarcinoma cell lines, OE19, OE33, SK-GT4 and OACM5.1c, were obtained from the European Collection of Cell Culture (ECACC). All were grown in RPMI-1640 (Gibco Invitrogen, Carlsbad, CA, USA), supplemented with $10 \%$ fetal bovine serum (FBS) and penicillin-streptomycin $9100 \mathrm{mg} / \mathrm{l}$; Invitrogen), at $37^{\circ} \mathrm{C}$ in a humidified atmosphere containing $5 \% \mathrm{CO}_{2}$.

Cell proliferation was assayed using the CCK-8 cell counting kit, according to the manufacturer's instructions. Briefly, cells $\left(5 \times 10^{3}\right)$ were seeded into each well of a 96-well plate and cultured in $100 \mu \mathrm{l}$ of RPMI-1640 supplemented with $10 \%$ FBS. After $24 \mathrm{~h}$, metformin $(0,1,5$ or $10 \mathrm{mM})$ was added to each well and cells were cultured for an additional $72 \mathrm{~h}$. CCK-8 reagent $(10 \mu \mathrm{l})$ was added to each well, and the plates were incubated at $37^{\circ} \mathrm{C}$ for $3 \mathrm{~h}$. The absorbance of each well was measured at $450 \mathrm{~nm}$ using a microplate reader.

Preparation of cell lysate. Cell lysates were prepared as described at $4^{\circ} \mathrm{C}$ (14). Protein concentrations were measured using a dye-binding protein assay based on the Bradford method (15).

Gel electrophoresis and western blotting. OE19 cells $\left(1.0 \times 10^{6} / \mathrm{dish}\right)$ were seeded in 100-mm culture dishes and cultured for $24 \mathrm{~h}$; metformin was added, and the cells were further cultured for $72 \mathrm{~h}$. The cells were lysed in protease-inhibitor cocktail ('Complete' protease inhibitor mixture; iNtRON Biotechnology; Sungnam; Korea) on ice for $20 \mathrm{~min}$. Suspensions of lysed cells were centrifuged at $13000 \mathrm{x} \mathrm{g}$ at $4^{\circ} \mathrm{C}$ for $5 \mathrm{~min}$; supernatants containing soluble cellular proteins were collected and stored at $-80^{\circ} \mathrm{C}$ until use. Protein concentrations were measured using a Nanodrop 2000 fluorospecrometer (Thermo Scientific Corp., USA). Protein aliquots (1-10 $\mu \mathrm{g}$ ) was resuspended in sample buffer and separated on $10 \%$ Tris-glycine gradient gels by SDS-PAGE (16), and the proteins were transferred to nitrocellulose membranes. After blocking, the membranes were incubated with primary antibodies and then were incubated with HRP-conjugated secondary antibodies (17). Immunoreactive proteins were visualized with an enhanced chemiluminescence detection system (Perkin-Elmer, Waltham, MA, USA) on X-ray film.

Flow cytometry. To evaluate the mechanism of growth inhibition by metformin, cell cycle profiles were analyzed after treatment with metformin. OE19 cells $\left(1.0 \times 10^{6}\right.$ cells in a $100-\mathrm{mm}$-diameter dish) were treated with or without $10 \mathrm{mmol} / \mathrm{l}$ metformin for $24-72 \mathrm{~h}$. The cell cycle was analyzed by measuring the amount of propidium iodide (PI)-labeled DNA in ethanol-fixed cells. Fixed cells were washed with PBS and then stored at $-20^{\circ} \mathrm{C}$ until analyzed by flow cytometry. On the day of analysis, the cells were washed with cold PBS, suspended in $100 \mu \mathrm{l}$ PBS plus $10 \mu \mathrm{l}$ RNaseA $(250 \mu \mathrm{g} / \mathrm{ml})$ and incubated for $30 \mathrm{~min}$. To each suspension was added $110 \mu \mathrm{l}$ PI stain $(100 \mu \mathrm{g} / \mathrm{ml})$, and the cells were incubated at $4^{\circ} \mathrm{C}$ for at least $30 \mathrm{~min}$ prior to analysis. Flow cytometry was performed on a Cytomics FC 500 flow cytometer (Beckman Coulter) with an argon laser $(488 \mathrm{~nm})$. The percentages of cells in different phases of the cell cycle were analyzed by FlowJo software (TreeStar, Ashland, OR, USA). All experiments were performed in triplicate to assess consistency of response.

Xenograftmodel analysis. Animal experiments were performed according to the guidelines of the Committee on Experimental Animals of Kagawa University, Kagawa, Japan. Thirty male athymic mice (BALB/c-nu/nu; 6 weeks old; 20-25 g) were purchased from Japan SLC Inc. and maintained under specific pathogen-free conditions using a laminar airflow rack. The mice had continuous free access to sterilized ( $\gamma$-irradiated) food (CL-2; CLEA Japan Inc.) and autoclaved water. Each mouse was subcutaneously inoculated with OE19 cells $\left(5 \times 10^{6}\right.$ cells per animal) in the flank. One week later, the xenografts were identifiable as masses of maximal diameter $>6 \mathrm{~mm}$. The animals were randomized to treatment with metformin or PBS. The metformin group was intraperitoneally (i.p.) injected five times per week with $2 \mathrm{mg} / \mathrm{kg}$ body weight per day metformin for two weeks; whereas the control group was administered PBS alone for 2 weeks. Tumor growth was monitored daily by the same investigators (S. Fujihara and T. Masaki), and tumor size was measured weekly by measuring the 2 greatest perpendicular dimensions. Tumor volume $\left(\mathrm{mm}^{3}\right)$ was calculated as tumor length $(\mathrm{mm}) \mathrm{x}$ tumor width $(\mathrm{mm})^{2} / 2$ (18). All animals were sacrificed on day 17 after treatment, with all remaining alive during this period. Between-group differences in tumor growth were analyzed by one-way ANOVA.

Antibody arrays of phosphorylated receptor tyrosine kinase $(p-R T K)$. Human phospho-RTK was assayed using Human phospho-RTK Array kits (R\&D Systems, Minneapolis, MN, USA), according to the manufacturer's instructions. Briefly, p-RTK array membranes were blocked with 5\% BSA/TBS (0.01 M Tris-HCl, $\mathrm{pH}$ 7.6) for $1 \mathrm{~h}$ and incubated with $2 \mathrm{ml}$ of lysate prepared from cell lines after normalization so that amounts of protein were equal. After 3 washes for $10 \mathrm{~min}$ each with TBS plus $0.1 \% \mathrm{v} / \mathrm{v}$ Tween-20 and 2 washes for 10 min with TBS alone to remove unbound materials, the membranes were incubated with anti-phospho-tyrosine-HRP antibody for $2 \mathrm{~h}$ at room temperature. The unbound HRP antibody was washed out with TBS plus $0.1 \%$ Tween-20. Finally, each array membrane was exposed to X-ray film using a chemiluminescence detection system (Perkin-Elmer Co.). The density of the immunoreactive band obtained on this array was analyzed by densiometric scanning (TIc scanner, Shimizu Co, Ltd., Kyoto, Japan). 
OE19

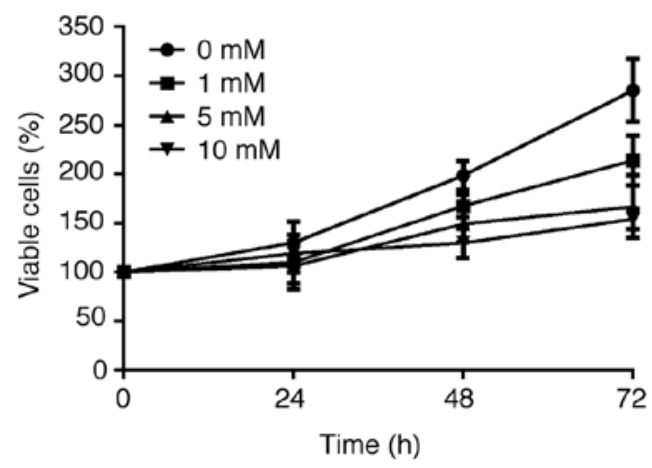

SK-GT4

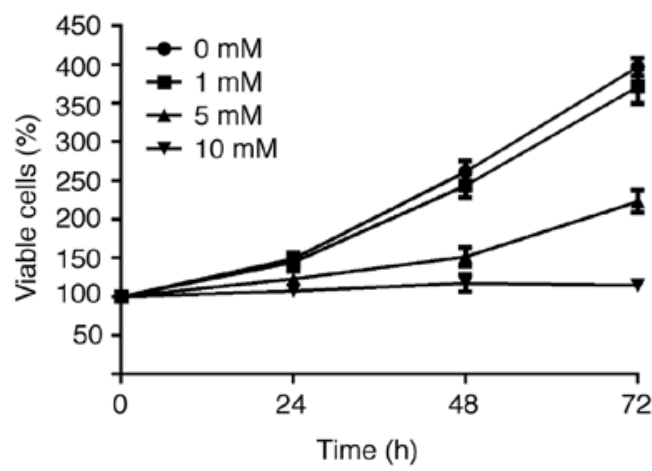

OE33

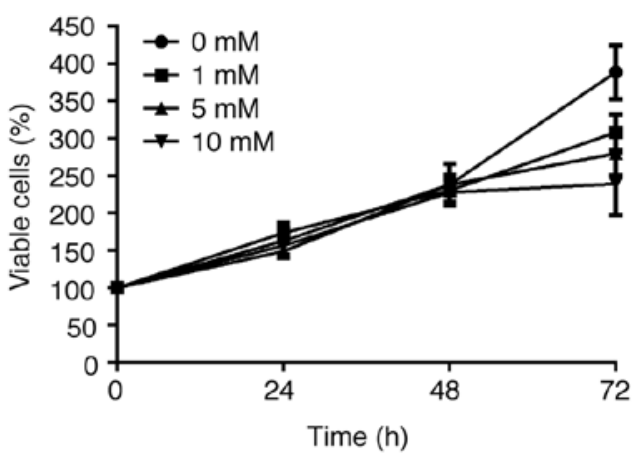

OACM 5.1C

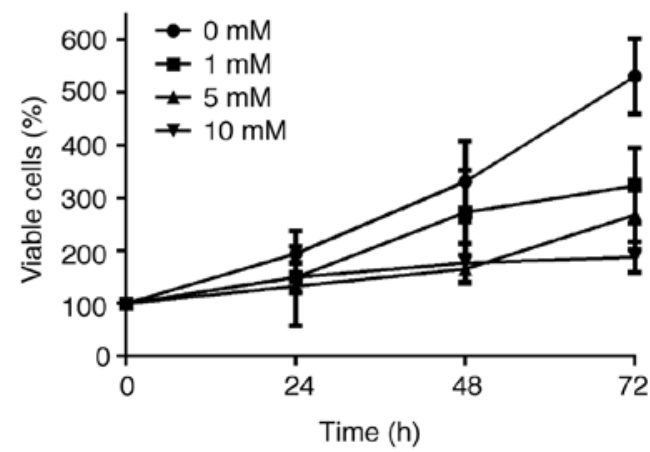

Figure 1. Metformin inhibits the proliferation of esophageal adenocarcinoma cells. OE19, OE33, SK-GT4 and OACM 5.1C cells were seeded in 96-well plates. After $24 \mathrm{~h}$, metformin $(1,5$, and $10 \mathrm{mmol} / \mathrm{l})$ or vehicle was added to the culture medium; $24 \mathrm{~h}$ later, cells were counted by the CCK assay. OE19, OE33, SK-GT4 and OACM 5.1C cells (5000/well) were seeded in 96-well plates and metformin was added as above. Cell viability was assayed daily from 0 to $72 \mathrm{~h}$; viability of metformin-treated cells differed significantly from the control cells $(\mathrm{P}<0.05)$.

Angiogenic profile analysis using an antibody array. The RayBio Human Angiogenesis Antibody Array (RayBiotech Inc.) was used according to the manufacturer's protocol. This method is a dot-based assay enabling detection and comparison of 20 angiogenesis-specific cytokines. Briefly, p-RTK array membranes were blocked with 5\% BSA/TBS $(0.01 \mathrm{M}$ Tris-HCl, $\mathrm{pH}$ 7.6) for $1 \mathrm{~h}$ and incubated with $2 \mathrm{ml}$ of lysate prepared from cell lines after normalization so that amounts of protein were equal. After 3 washes for 10 min each with TBS plus $0.1 \% \mathrm{v} / \mathrm{v}$ Tween-20 and 2 washes for 10 min with TBS alone to remove unbound materials, the membranes were incubated with anti-phospho-tyrosine-HRP antibody for $2 \mathrm{~h}$ at room temperature. The unbound HRP antibody was washed out with TBS including $0.1 \%$ Tween-20. Finally, each array membrane was exposed to X-ray film using a chemiluminescence detection system (PerkinElmer Co.). The density of the immunoreactive band obtained on this array was analyzed by densiometric scanning (TIc scanner, Shimizu Co., Ltd.).

Analysis of miRNA arrays. Total RNA was extracted from tumor samples and cancer cell lines using miRNeasy Mini kits (Qiagen, Hilden, Germany) according to the manufacturer's instructions. RNA samples typically showed $A_{260 / 280}$ ratios between 1.9 and 2.1, using an Agilent 2100 Bioanalyzer (Agilent Technologies, Santa Clara, CA, USA).

After RNA measurement with an RNA 6000 Nano kit (Agilent Technologies), the samples were labeled using a miRCURYHy3/Hy5 Power Labeling kit and were hybridized to a human miRNA Oligo chip (v.14.0; Toray Industries,

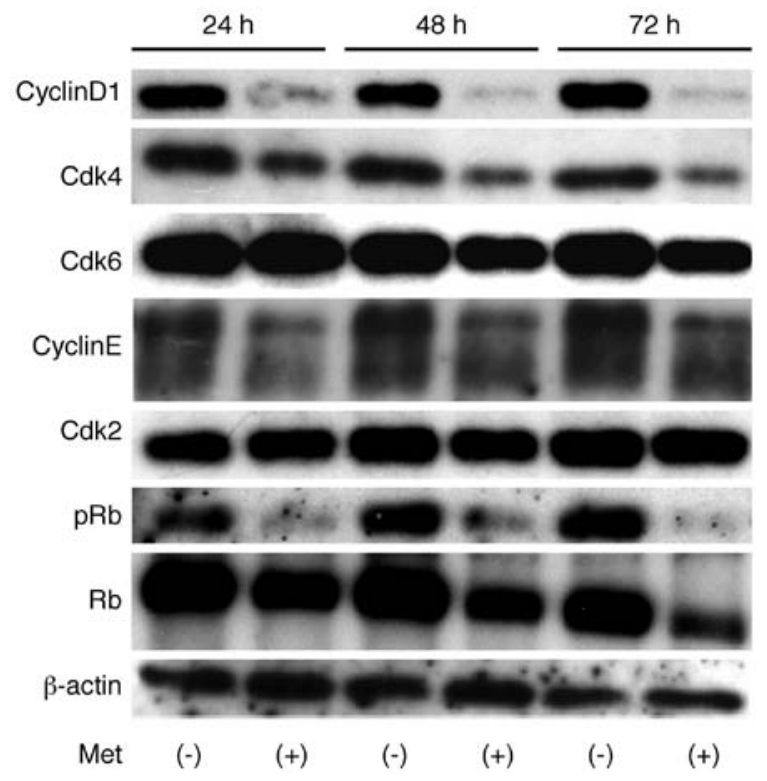

Figure 2. Expression of cyclin D1, Cdk4, Cdk6, cyclin E, Cdk2, phospholylated $\mathrm{Rb}(\mathrm{pRb})$ and $\mathrm{Rb}$ in OE19 cells 24,48 , and $72 \mathrm{~h}$ after the addition of $10 \mathrm{mmol} / 1 \mathrm{metformin}$. Protein expression was assayed by western blotting.

Tokyo, Japan). The chips were scanned with a 3-D Gene Scanner 3000 (Toray Industries), and the results analyzed by 3D-Gene extraction version 1.2 software (Toray Industries). Differences in miRNA expression between metformin-treated and control samples were assessed by analyzing the raw data 

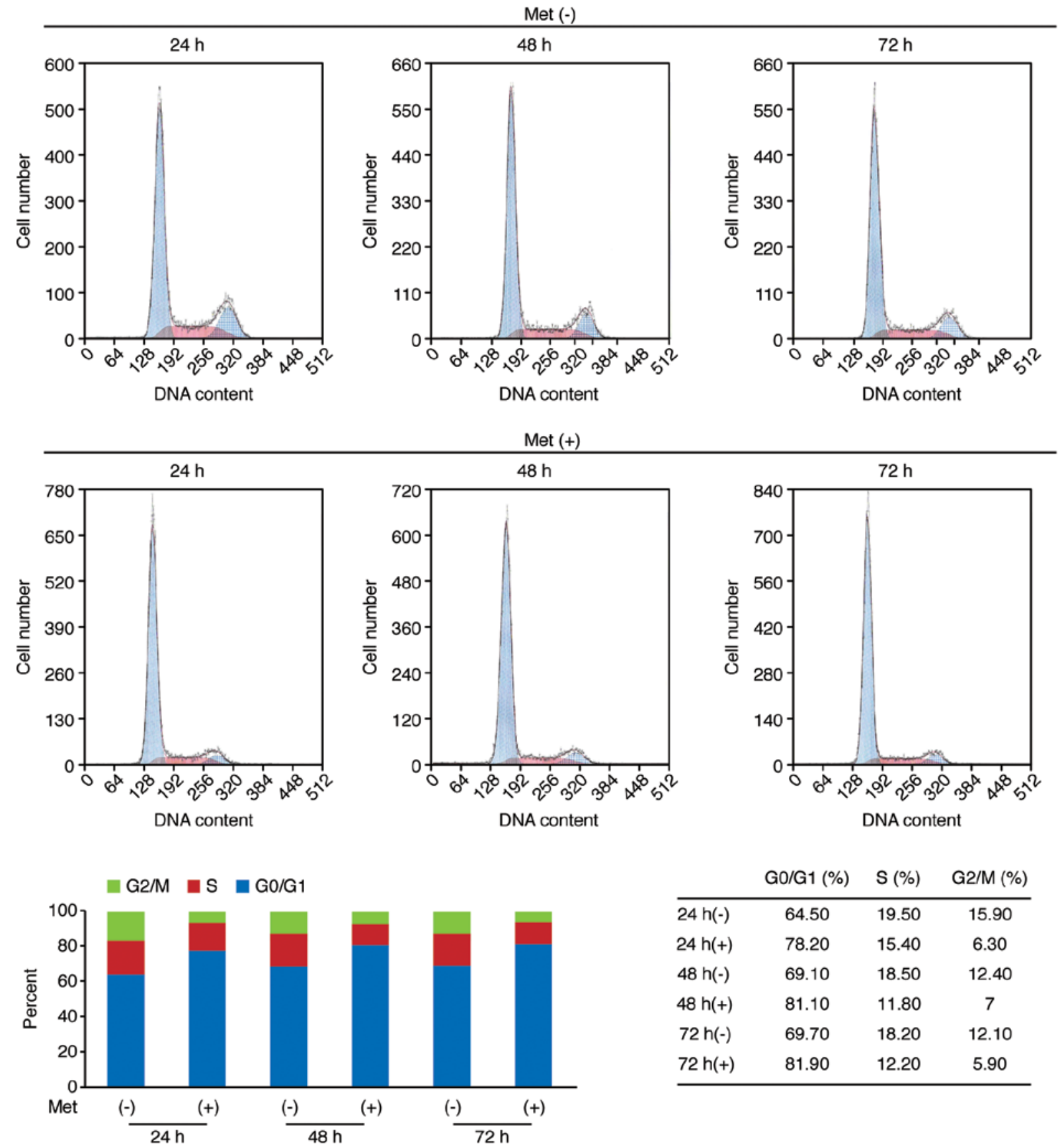

\begin{tabular}{lccc} 
& G0/G1 (\%) & S (\%) & G2/M (\%) \\
\hline $24 \mathrm{~h}(-)$ & 64.50 & 19.50 & 15.90 \\
$24 \mathrm{~h}(+)$ & 78.20 & 15.40 & 6.30 \\
$48 \mathrm{~h}(-)$ & 69.10 & 18.50 & 12.40 \\
$48 \mathrm{~h}(+)$ & 81.10 & 11.80 & 7 \\
$72 \mathrm{~h}(-)$ & 69.70 & 18.20 & 12.10 \\
$72 \mathrm{~h}(+)$ & 81.90 & 12.20 & 5.90 \\
\hline
\end{tabular}

Figure 3. Flow cytometric analysis of proliferating OE19 cells 24,48 and $72 \mathrm{~h}$ after addition of $10 \mathrm{mmol} / 1$ metformin (Met). Metformin blocked the cell cycle in $G_{0}-G_{1}$. Results are representative of 3 independent experiments.

using GeneSpringGX v10.0 (Agilent Technologies). Samples were first normalized relative to $28 \mathrm{~S}$ RNA and baseline corrected to the median of all samples.

Replicate data were consolidated into 2 groups: those from metformin-treated cells and those from control cells and were organized using the hierarchical clustering and ANOVA functions in GeneSpring software. Hierarchical clustering was performed using the use clustering function (condition tree) and Euclidean correlation as a distance metric. Two-way ANOVA analysis and asymptotic P-value computation without any error correction on the samples were performed to determine the miRNAs varying most prominently across the groups. The P-value cutoff was set to 0.05 . Only changes $>50 \%$ for at least one of the time points for each sample were considered significant. All the analyzed data were scaled by global normalization. The statistical significance of differentially expressed miRNAs was analyzed by Student's t-test.

Statistical analysis. All statistical analyses were performed using computer assisted JMP 9.0 (SAS Institute, Cary, NC, USA). Paired analysis between groups used t-tests. A P-value $<0.05$ was considered statistically significant.

\section{Results}

Metformin inhibits the proliferation of human esophageal adenocarcinoma cancer cells. The effect of metformin on the proliferation of four esophageal adenocarcinoma cell 


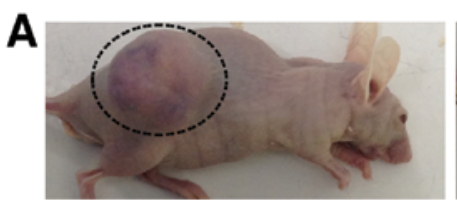

a) Control

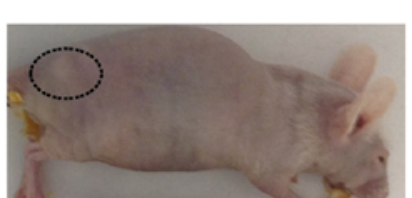

b) Met $2 \mathrm{mg} / \mathrm{d}$

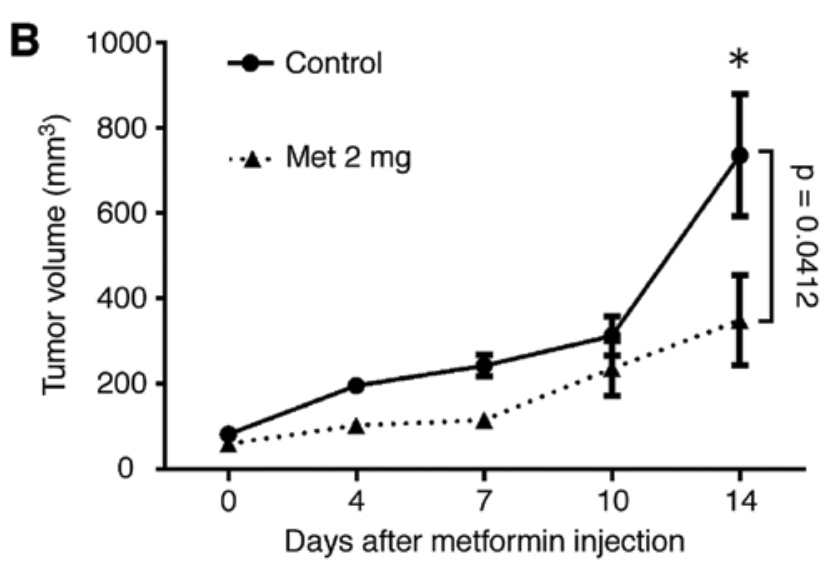

Figure 4. In vivo antitumor effect of metformin on established esophageal adenocarcinomas in nude mice. OE19 cells were implanted subcutaneously into the flanks of nude mice. When tumors became palpable, 0 or $2 \mathrm{mg}$ metformin was injected intraperitoneally for 2 weeks, 5 times per week. (A) Representative images of gross OE19 tumors from nude mice treated with vehicle i) or $2 \mathrm{mg}$ metformin ii). (B) Tumor growth curves in the control and metformin groups. Tumor volume $\left(\mathrm{mm}^{3}\right)$ was calculated as (tumor length $(\mathrm{mm}) \mathrm{x}$ tumor width $\left.(\mathrm{mm})^{2}\right) / 2$. Tumors were significantly smaller in metformin than in vehicle-treated mice. Each point represents the mean \pm standard deviation of 10 animals. $\mathrm{P}=0.412$ by one-way ANOVA.

lines, OE19, OE33, SK-GT4 and OACM5.1c, was evaluated. Cells were grown in $10 \%$ FBS and treated with $0,1,5$ or $10 \mathrm{mmol} / 1 \mathrm{metformin}$ for $72 \mathrm{~h}$. Metformin showed a strong, dose-dependent inhibition of cell proliferation of all four esophageal adenocarcinoma cell lines (Fig. 1).

Effects of metformin on cell cycle regulatory proteins in OE19. The effects of metformin on the expression of various cell cyclerelated molecules in OE19 cells were evaluated by western blotting. Cells were treated with 0 or $10 \mathrm{mmol} / \mathrm{l}$ metformin for 24-72 $\mathrm{h}$. The most marked metformin-associated change was the loss of cyclin D1, a key protein implicated in the transition from $G_{0}$ to $G_{1}$ phase, which showed a time-dependent reduction (Fig. 2). Metformin treatment also resulted in a progressive decrease in phosphorylated $\mathrm{Rb}$, but had no effect on total $\mathrm{Rb}$. Assays of the expression of other proteins associated in the $G_{0}$ to $G_{1}$ transition showed that Cdk6, the catalytic subunit of cyclin D1, Cdk4, and cyclin E were decreased 48 and $72 \mathrm{~h}$ after the addition of metformin.

To further the mechanism of action of metformin on OE19 cell proliferation, cell cycle progression was examined by flow cytometry. Following the addition of $10 \mathrm{mmol} / \mathrm{l}$ metformin, an increasing number of cells started accumulating in $\mathrm{G}_{0}-\mathrm{G}_{1}$, $78.2 \%$ after $24 \mathrm{~h}, 81.1 \%$ after $48 \mathrm{~h}$, and $81.9 \%$ after $72 \mathrm{~h}$ (Fig. 3). This was accompanied by reductions in the percentages of cells in $\mathrm{S}-$ and $\mathrm{G}_{2}-\mathrm{M}$ phase (Fig. 3). These findings suggest that metformin inhibits cell cycle progression from $G_{0}-G_{1}$ into S-phase, resulting in $G_{1}$ cell cycle arrest.
Table I. Statistical results and chromosomal location of miRNAs in OE19 cells treated with and without metformin.

\begin{tabular}{|c|c|c|c|}
\hline miRNA & $\begin{array}{c}\text { Fold } \\
\text { (treated/nontreated), } \\
\text { mean } \pm \mathrm{SD}\end{array}$ & P-value & $\begin{array}{c}\text { Chromosomal } \\
\text { localization }\end{array}$ \\
\hline \multicolumn{4}{|l|}{ Upregulated } \\
\hline hsa-miR-1246 & $6.25 \pm 3.29$ & 0.0107 & $2 \mathrm{q} 31.1$ \\
\hline hsa-miR-6131 & $4.90 \pm 2.87$ & 0.0216 & 5 \\
\hline hsa-miR-6087 & $3.55 \pm 1.26$ & 0.0230 & $\mathrm{X}$ \\
\hline hsa-miR-4484 & $3.08 \pm 1.01$ & 0.0190 & 10 \\
\hline hsa-miR-1237-5p & $2.93 \pm 0.96$ & 0.0109 & 11 \\
\hline hsa-miR-6784-5p & $2.91 \pm 1.34$ & 0.0341 & 17 \\
\hline hsa-miR-762 & $2.77 \pm 0.92$ & 0.0103 & 16 \\
\hline hsa-miR-6780b-5p & $2.75 \pm 1.53$ & 0.0419 & 6 \\
\hline hsa-miR-204-3p & $2.71 \pm 1.14$ & 0.0445 & $9 q 21.12$ \\
\hline hsa-miR-3196 & $2.69 \pm 1.15$ & 0.0323 & 20 \\
\hline hsa-miR-6768-5p & $2.68 \pm 0.97$ & 0.0051 & 16 \\
\hline hsa-miR-4734 & $2.66 \pm 1.05$ & 0.0216 & 17 \\
\hline hsa-miR-6869-5p & $2.64 \pm 1.33$ & 0.0238 & 20 \\
\hline hsa-miR-6726-5p & $2.57 \pm 1.53$ & 0.0444 & 1 \\
\hline hsa-miR-8069 & $2.56 \pm 1.11$ & 0.0478 & 21 \\
\hline hsa-miR-6786-5p & $2.46 \pm 0.80$ & 0.0431 & 17 \\
\hline hsa-miR-4508 & $2.45 \pm 0.79$ & 0.0147 & 15 \\
\hline hsa-miR-6132 & $2.42 \pm 0.68$ & 0.0241 & 7 \\
\hline hsa-miR-6727-5p & $2.41 \pm 0.96$ & 0.0469 & 1 \\
\hline hsa-miR-4651 & $2.35 \pm 1.33$ & 0.0487 & 7 \\
\hline hsa-miR-3621 & $2.35 \pm 1.04$ & 0.0208 & 9 \\
\hline hsa-miR-3656 & $2.32 \pm 0.69$ & 0.0213 & 11 \\
\hline hsa-miR-21-5p & $2.28 \pm 1.07$ & 0.0348 & $17 q 23.1$ \\
\hline hsa-miR-4466 & $2.27 \pm 0.84$ & 0.0455 & 6 \\
\hline hsa-miR-3665 & $2.22 \pm 092$ & 0.0470 & 13 \\
\hline hsa-miR-1908-5p & $2.12 \pm 0.85$ & 0.0490 & 11 \\
\hline hsa-miR-5787 & $2.06 \pm 0.75$ & 0.0409 & 3 \\
\hline hsa-miR-1228-5p & $2.00 \pm 0.80$ & 0.0392 & 12 \\
\hline hsa-miR-215-5p & $1.76 \pm 0.64$ & 0.0499 & $1 \mathrm{q} 41$ \\
\hline hsa-miR-4730 & $1.19 \pm 0.66$ & 0.0108 & 17 \\
\hline \multicolumn{4}{|l|}{ Downregulated } \\
\hline hsa-miR-4699-3p & $0.31 \pm 0.35$ & 0.0440 & 12 \\
\hline hsa-miR-1915-5p & $0.44 \pm 0.34$ & 0.0035 & $10 \mathrm{p} 12.31$ \\
\hline hsa-miR-483-3p & $0.52 \pm 0.31$ & 0.0356 & $11 \mathrm{p} 15.5$ \\
\hline hsa-miR-6869-3p & $0.58 \pm 0.27$ & 0.0270 & 20 \\
\hline hsa-miR-6716-5p & $0.59 \pm 0.44$ & 0.0215 & 11 \\
\hline hsa-miR-874-3p & $0.62 \pm 0.31$ & 0.0372 & $5 q 31.2$ \\
\hline hsa-miR-3181 & $0.64 \pm 0.27$ & 0.0117 & 16 \\
\hline hsa-miR-1234-3p & $0.64 \pm 0.29$ & 0.0467 & 8 \\
\hline hsa-miR-1302 & $0.71 \pm 0.30$ & 0.0426 & $\mathrm{X}$ \\
\hline hsa-miR-1914-5p & $0.71 \pm 0.30$ & 0.0408 & $20 q 13.33$ \\
\hline
\end{tabular}

Metformin inhibits tumor proliferation in vivo. To determine whether metformin could affect tumor growth in vivo, nude mice were injected subcutaneously with OE19 cells, followed by the i.p. injection of metformin. Based on integrated tumor 
A

\begin{tabular}{|c|c|c|c|c|c|c|c|c|c|c|c|}
\hline $\begin{array}{c}\text { Reference } \\
\text { Spots }\end{array}$ & & & & & & & & & & & \begin{tabular}{|c|} 
Reference \\
Spots
\end{tabular} \\
\hline EGF R i & ErbB2i & ErbB3 & : ErbB4 & FGF R1 & FGF $\alpha$ R2 & FGF R3 & FGF R4 i & Insulin Ri & IGF-1 R & $A x \mid$ & Dtk \\
\hline Mer & $\mathrm{HGF}$ & MSP R & PDGFR $\alpha$ & PDGFR $\beta$ & SCF R & Flt-3 & M-CSF R & C-Ret & ROR1 & ROR2 & Tie-1 \\
\hline Tie-2 & TrkA & TrkB & TrkC & VEGF R1 & VEGF R2 & VEGF R3 & MuSK & EphA1 & EphA2 & EphA3 & EphA4 \\
\hline EphA6 & EphA7 & EphB1 & EphB2 & EphB4 & EphB6 & ALK & DDR1 & DDR2 & EphA5 & EphA10 & \\
\hline \begin{tabular}{|c|} 
Reference \\
Spots
\end{tabular} & & EphB3 & PYK & & & & & & & & PBS \\
\hline
\end{tabular}

B
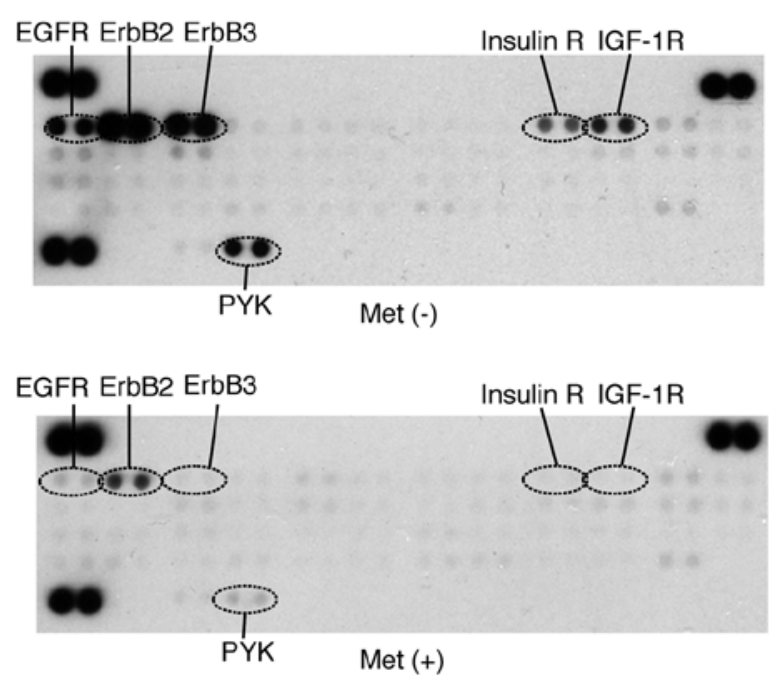

C

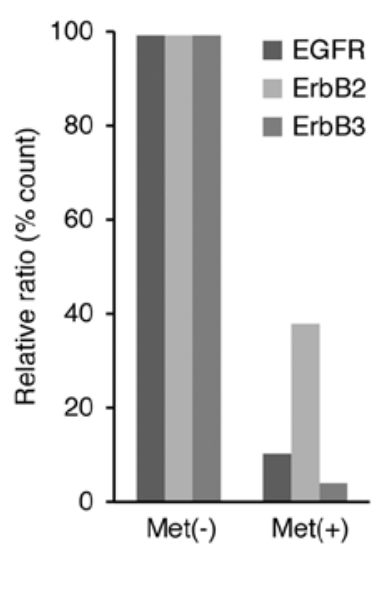

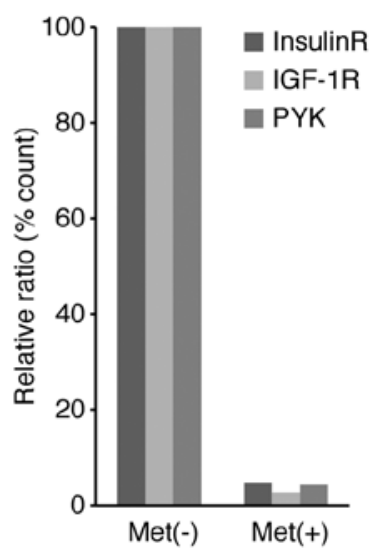

Figure 5. (A) Template showing the location of tyrosine kinase antibodies spotted onto a human phospho-RTK array. (B) Representative expression of various phosphorylated tyrosine kinase receptors in OE19 cells treated with or without metformin. (C) The densitometric ratios of the p-EGFR, ErbB2 and ErbB3 spots of the metformin-treated to untreated cells were $10.8,38.4$ and 4.6\%, respectively. The densitometric ratios of the p-IGF-1R, insulin R and PYK spots of the metformin-treated to untreated cells were $2.5,4.7$ and $4.4 \%$, respectively.

A

\begin{tabular}{|c|c|c|c|c|c|c|c|}
\hline Positive & Positive & Negative & Negative & Angiogenin & EGF & ENA-78 & $\beta$ FGF \\
\hline GRO & IFN- $\gamma$ & IGF-1 & IL-6 & IL-8 & LEPTIN & MCP-1 & PDGF-BB \\
\hline PIGF & RANTES & TGF- $\beta 1$ & TIMP-1 & TIMP-2 & Thrombopoietin & VEGF & VEGF-D \\
\hline & & & & & & Negative & Positive \\
\hline
\end{tabular}

B

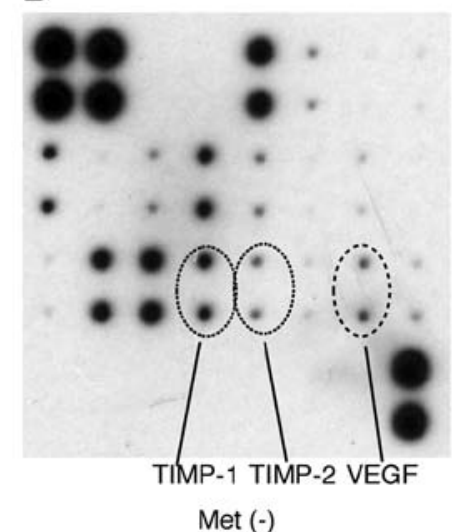

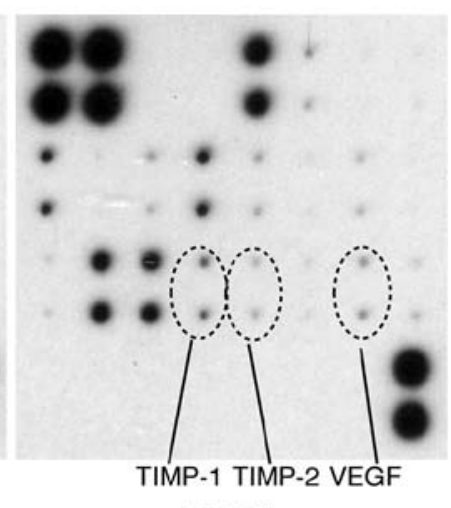

Met (+)

\section{C}

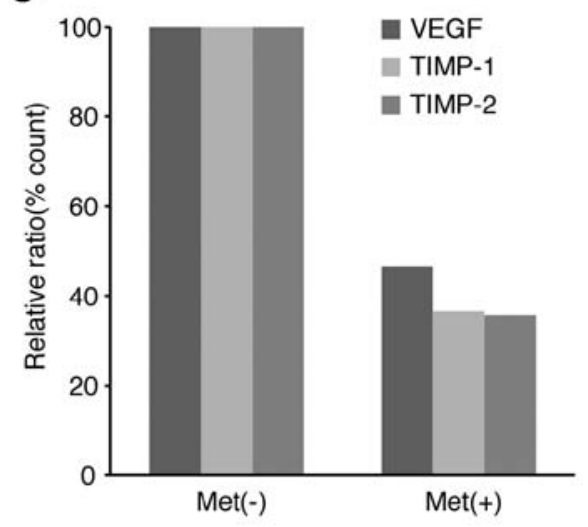

Figure 6. (A) Template showing the location of angiogenesis-related proteins spotted onto a human angiogenesis array. (B) Representative expression of various angiogenesis-related proteins in OE19 cells treated with or without metformin. (C) The densitometric ratios of the VEGF, TIMP-1 and TIMP-2 spots of the metformin-treated to untreated cells were $46.5,36.6$ and $35.6 \%$, respectively. 
growth curves, the i.p. metformin substantially inhibited tumor growth, by $47 \%$ (Fig. 4A and B), compared with untreated control mice. Throughout this study, metformin had no apparent effects on the mice and did not affect their weight. All animals remained alive during the experiment.

Effects of metformin on p-RTKs in vitro and in vivo. A p-RTK array system was used to identify the key RTKs associated with the antitumor effect of metformin. Using an antibody array (Fig. 5A) enabled the expression of 49 activated RTKs to be screened in OE19 cells and tumors in the presence and absence of metformin. Metformin reduced the levels of expression of phosphorylated epidermal growth factor receptor (p-EGFR) and phosphorylated insulin-like growth factor-1 receptor (p-IGF-1R) in vitro, as well as reducing the expression of ErbB2, ErbB3, insulin-R and PYK (Fig. 5B).

Densitometry showed that ratios of p-EGFR, ErbB2 and ErbB3 spots of metformin-treated to untreated cells were 10.8, 38.4 and $4.6 \%$, respectively (Fig. 5C). The densitometric ratios of p-IGF-1R, insulin R, and PYK spots of metformin-treated to untreated cells were 2.5, 4.7 and $4.4 \%$, respectively (Fig. 5C).

Effects of metformin on angiogenesis in vitro and in vivo. We used an angiogenesis array system (Fig. 6A) to identify the key angiogenesis-related molecules associated with the antitumor effects of metformin on OE19 cells. Of the 20 angiogenesis molecules screened, VEGF, TIMP-1, and TIMP-2 were reduced in vitro by metformin (Fig. 6B). The densitometric ratios of VEGF, TIMP-1 and TIMP-2 spots of metformin-treated to untreated cells were 46.5, 36.6 and $35.6 \%$, respectively (Fig. 6C).

Effects of metformin on miRNA expression. Using a custom microarray platform, we analyzed the levels of expression of 985 miRNA probes in cell lines and tumor tissues in the presence and absence of metformin. Treatment of OE19 cells with $10 \mathrm{mmol} / \mathrm{l}$ metformin for $72 \mathrm{~h}$ significantly upregulated three miRNAs while significantly downregulating 10 miRNAs (Table I).

Unsupervised hierarchical clustering analysis, using Pearson's correlation, showed that cell lines in vitro and tumorous tissues in vivo treated with metformin clustered together, and separately from untreated cell lines (Fig. 7).

\section{Discussion}

Esophageal cancer is the eight most common cancer and the sixth most common cause of cancer deaths worldwide (19). The incidence of esophageal adenocarcinoma (EAC) has been increasing, particularly in western countries, accounting for $50 \%$ of esophageal cancers (20). Obese patients have a higher prevalence of gastroesophageal reflux disease, which can lead to Barrett's esophagus and intestinal metaplasia, which are precursors of EAC (21-23).

Metformin (dimethylbiguanide) is one of the most commonly prescribed antihyperglycemic drugs for the treatment of type 2 diabetes worldwide. The mechanism of action of metformin includes the stimulation of glucose uptake and the increase in fatty acid oxidation in muscle and liver (5). These properties can result in the inhibition of cancer cell

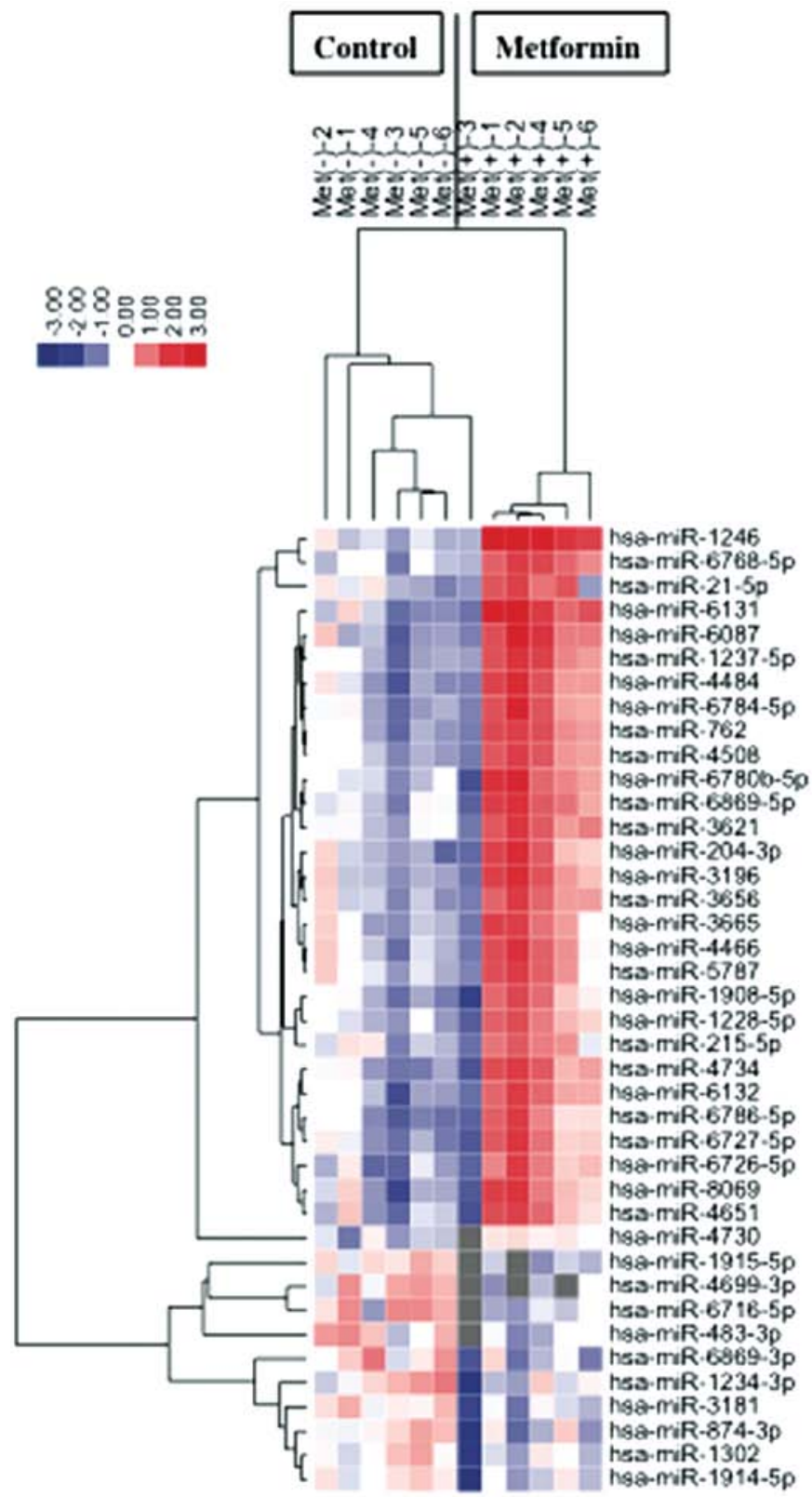

Figure 7. Hierarchical clustering of OE19 cells with and without metformin. OE19 cells were clustered according to the expression profiles of 32 miRNAs differentially expressed by OE19 cells with and without metformin. The analyzed samples are shown in the columns and the miRNAs are presented in rows. The miRNA clustering color scale shown at the top shows the relative expression levels of miRNAs; with red and blue representing high and low expression levels, respectively.

growth, the suppression of HER2 overexpression and the inhibition of mTOR (24-26). Metformin has also been shown to block cancer cell proliferation (5,10-13), and to reduce the risk of esophagus, stomach, colon, pancreas and liver cancer, and improve cancer prognosis, in patients with type 2 diabetes (27).

However, the antitumor effect of metformin on EAC remained unknown. Herein, we show that metformin not only is a very potent inhibitor of human esophageal adenocarcinoma cell growth but also inhibits tumorigenesis in a xenograft model when administered intraperitoneally.

Specific cyclin/Cdk complexes are activated at different intervals during the cell cycle. Complexes of Cdk4 and Cdk6 with cyclin D1 are required for G1 phase progression, whereas 
complexes of $\mathrm{Cdk} 2$ with cyclin $\mathrm{E}$ are required for $\mathrm{G} 1-\mathrm{S}$ transition (28). Metformin has been shown to downregulate cyclin D1 in various cancer cell lines, including stomach (11), colon (10), liver (13), breast (9), and prostate (5) cancer lines. However, the effects of metformin on catalytic subunits of cyclin D1, Cdk4 and Cdk6, remain unknown. The results presented here indicate that these major cell cycle regulators (cyclin D1, Cdk4, Cdk6, cyclinE, Cdk2 and phosphorylated Rb) may be intracellular targets of the metformin-mediated antiproliferative effect in human esophageal adenocarcinoma cell lines. In addition, flow cytometry showed that metformin arrested esophageal adenocarcinoma cells at the $G_{0}$ to $G_{1}$ transition in vitro. Metformin also markedly suppressed the growth of subcutaneous esophageal adenocarcinomas in athymic nude mice reducing the levels of expression of cyclin D1, Cdk4, Cdk6, cyclin E, Cdk2 and phosphorylated Rb in these tumors, indicating that metformin may inhibit the expression of cell cycle-related molecules in vivo. These data suggest that the antitumor effect of metformin may be related to the reduction of various cell cycle-related proteins, especially cyclin D1.

An in vitro study was conducted using a higher dose of metformin than used in human treatment (6-30 $\mu \mathrm{mol} / \mathrm{l})$. The use of such higher doses has been the subject of criticism of similar studies in other cancer cell types, such as breast (9), prostate (5), and colon cancer (10) cells. However, cells in culture are grown under hyperglycemic conditions (29). Tissue culture medium alone contains high concentrations of glucose, and 5-10\% FBS is typically added, resulting in excessive growth stimulation. This may explain why the antitumor effects of metformin in cell culture systems require higher doses than are used in patients with diabetes.

The expression of various cell cycle-related molecules, including cyclin D1 Cdk4, Cdk6, cyclinE and Cdk2, has been found to be enhanced in various cancers $(30,31)$. Therefore, inhibition of these molecules, including cycle D1, may be a target for controlling tumor proliferation.

Metformin has been found to alter the phosphorylation of various proteins, including Akt, $\beta$-catenin, CREB and Chk2 (32), and c-Src (29), in various cell lines. Using protein arrays, we found that metformin reduced $\mathrm{p}$-EGFR and p-IGF-1R in esophageal adenocarcinoma cells. Metformin has also been reported to reduce the levels of expression of p-EGFR and p-IGF-1R in breast (29), and pancreatic (33) cancers. Together, these studies suggest that metformin might reduce the expression levels of levels of p-EGFR and p-IGF in many cancer types, including esophageal adenocarcinoma. The EGFR pathway is important in controlling cell cycle events. For example, EGFR activation was found to induce expression of cyclin D1, a protein important in cell cycle progression $(34,35)$.

Metformin also reduced the level of VEGF expression, a key mediator in cancer angiogenesis, a process essential for cancer development and growth (42). High VEGF expression has been associated with poor prognosis in patients with esophageal cancer, suggesting that reducing its expression may have benefits in patients with esophageal cancers (43). Moreover, metformin was found to reduce expression of TIMP-1 and TIMP-2, both of which are angiogenesis-related proteins. TIMP-1 inhibits the activity of matrix metalloproteinases, which play an important role in cancer invasion and metastasis (36).
TIMP-1 expression has been found to correlate with highgrade malignant behavior in human esophageal carcinomas, and is an independent prognostic factor in these patients (37). These results suggest that the antitumor effect of metformin may be due, at least in part, to its reduction of TIMP-1 expression, and may therefore play an important role in reducing cancer invasion and metastasis.

The miRNAs associated with the antitumor effects of metformin were assessed using miRNA expression arrays. Cluster analyses clearly showed that metformin treatment affected the extent of miRNA expression in clustered cells and in tumor tissues. We identified 40 miRNAs that were differentially expressed in cluster. These miRNAs are meaningful candidates to gauge the effectiveness of metformin treatment and to provide clues to the molecular basis of the anti-cancer effects of metformin, particularly those mediated by miRNAs.

MiR-1246 was reported to be a target of the p53 family, and inhibits Down syndrome-associated DYRK1A, consequently activating NFAT1c and inducing apoptosis (38). Serum miR-1246 was reported elevated in patients with esophageal squamous cell carcinoma, to correlate with TNM stage and to be an independent risk factor for poor survival (39). Other studies have also shown contrasting changes in the miRNA expression levels between tissue and blood samples $(40,41)$. It has not yet been determined whether miR-1246 acts as an oncogenic miRNA or tumor suppressor. However, metformin was shown to upregulate miR-1246 in gastric cancer (11), esophageal squamous cell carcinoma (12), and hepatocellular carcinoma (13) cell lines, suggesting that miR-1246 may be associated with the antitumor effect of metformin in various cancer cells.

In conclusion, our results revealed that metformin inhibits human esophageal adenocarcinoma cell proliferation and tumor growth, possibly by suppressing cell cycle-related molecules through the alteration of miRNAs.

\section{Acknowledgements}

We thank Ms. Yuko Miyawaki and Ms. Noriko Murao for providing technical assistance.

\section{References}

1. Pennathur A, Gibson MK, Jobe BA and Luketich JD: Oesophageal carcinoma. Lancet 381: 400-412, 2013.

2. Enzinger PC and Mayer RJ: Esophageal cancer. N Engl J Med 349: 2241-2252, 2003

3. Pennathur A, Farkas A, Krasinskas AM, Ferson PF, Gooding WE, Gibson MK, Schuchert MJ, Landreneau RJ and Luketich JD: Esophagectomy for T1 esophageal cancer: Outcomes in 100 patients and implications for endoscopic therapy. Ann Thorac Surg 87: 1048-1055, 2009.

4. Edgren G, Adami HO, Weiderpass E and Nyrén O: A global assessment of the oesophageal adenocarcinoma epidemic. Gut 62: 1406-1414, 2013.

5. Ben Sahra I, Laurent K, Loubat A, Giorgetti-Peraldi S, Colosetti P, Auberger P, Tanti JF, Le Marchand-Brustel Y and Bost F: The antidiabetic drug metformin exerts an antitumoral effect in vitro and in vivo through a decrease of cyclin D1 level. Oncogene 27: 3576-3586, 2008.

6. Libby G, Donnelly LA, Donnan PT, Alessi DR, Morris AD and Evans JM: New users of metformin are at low risk of incident cancer: A cohort study among people with type 2 diabetes. Diabetes Care 32: 1620-1625, 2009. 
7. Landman GW, Kleefstra N, van Hateren KJ, Groenier KH, Gans RO and Bilo HJ: Metformin associated with lower cancer mortality in type 2 diabetes: ZODIAC-16. Diabetes Care 33: 322-326, 2010

8. Kourelis TV and Siegel RD: Metformin and cancer: New applications for an old drug. Med Oncol 29: 1314-1327, 2012

9. Anisimov VN, Egormin PA, Piskunova TS, Popovich IG Tyndyk ML, Yurova MN, Zabezhinski MA, Anikin IV, Karkach AS and Romanyukha AA: Metformin extends life span of HER-2/neu transgenic mice and in combination with melatonin inhibits growth of transplantable tumors in vivo. Cell Cycle 9: 188-197, 2010.

10. Zhou XZ, Xue YM, Zhu B and Sha JP: Effects of metformin on proliferation of human colon carcinoma cell line SW-480. Nan Fang Yi Ke Da Xue Xue Bao 30: 1935-1938, 1942, 2010 (In Chinese)

11. Kato K, Gong J, Iwama $\mathrm{H}$, et al: The antidiabetic drug metformin inhibits gastric cancer cell proliferation in vitro and in vivo. Mol Cancer Ther 11: 549-560, 2012.

12. Kobayashi M, Kato K, Iwama $\mathrm{H}$, et al: Antitumor effect of metformin in esophageal cancer: In vitro study. Int J Oncol 42: 517-524, 2013.

13. Miyoshi H, Kato K, Iwama H, et al: Effect of the anti-diabetic drug metformin in hepatocellular carcinoma in vitro and in vivo. Int J Oncol 45: 322-332, 2014.

14. Masaki T, Tokuda M, Yoshida S, et al: Comparison study of the expressions of myristoylated alanine-rich $C$ kinase substrate in hepatocellular carcinoma, liver cirrhosis, chronic hepatitis, and normal liver. Int J Oncol 26: 661-671, 2005.

15. Bradford MM: A rapid and sensitive method for the quantitation of microgram quantities of protein utilizing the principle of protein-dye binding. Anal Biochem 72: 248-254, 1976.

16. Laemmli UK: Cleavage of structural proteins during the assembly of the head of bacteriophage T4. Nature 227: 680-685, 1970.

17. Towbin H, Staehelin T and Gordon J: Electrophoretic transfer of proteins from polyacrylamide gels to nitrocellulose sheets: Procedure and some applications. Proc Natl Acad Sci USA 76: 4350-4354, 1979

18. D'Incalci M, Colombo T, Ubezio P, et al: The combination of yondelis and cisplatin is synergistic against human tumor xenografts. Eur J Cancer 39: 1920-1926, 2003.

19. Ferlay J, Shin HR, Bray F, Forman D, Mathers C and Parkin DM Estimates of worldwide burden of cancer in 2008: GLOBOCAN 2008. Int J Cancer 127: 2893-2917, 2010.

20. Bird-Lieberman EL and Fitzgerald RC: Early diagnosis of oesophageal cancer. Br J Cancer 101: 1-6, 2009.

21. Solaymani-Dodaran M, Logan RF, West J, Card T and Coupland C: Risk of oesophageal cancer in Barrett's oesophagus and gastro-oesophageal reflux. Gut 53: 1070-1074, 2004.

22. Falk GW: Barrett's esophagus. Gastroenterology 122: 1569-1591, 2002.

23. Fujihara S, Mori H, Kobara H, Nishiyama N, Kobayashi M, Oryu $\mathrm{M}$ and Masaki T: Metabolic syndrome, obesity, and gastrointestinal cancer. Gastroenterol Res Pract 2012: 483623, 2012.

24. Alimova IN, Liu B, Fan Z, Edgerton SM, Dillon T, Lind SE and Thor AD: Metformin inhibits breast cancer cell growth, colony formation and induces cell cycle arrest in vitro. Cell Cycle 8 : 909-915, 2009

25. Vazquez-Martin A, Oliveras-Ferraros C and Menendez JA: The antidiabetic drug metformin suppresses HER2 (erbB-2) oncoprotein overexpression via inhibition of the mTOR effector p70S6K1 in human breast carcinoma cells. Cell Cycle 8: 88-96, 2009.

26. Vázquez-Martín A, Oliveras-Ferraros C, del Barco S, MartínCastillo B and Menéndez JA: mTOR inhibitors and the anti-diabetic biguanide metformin: New insights into the molecular management of breast cancer resistance to the HER2 tyrosine kinase inhibitor lapatinib (Tykerb). Clin Transl Oncol 11: 455-459, 2009.
27. Franciosi M, Lucisano G, Lapice E, Strippoli GF, Pellegrini F and Nicolucci A: Metformin therapy and risk of cancer in patients with type 2 diabetes: Systematic review. PLoS One 8: e71583, 2013

28. Masaki T, Shiratori Y, Rengifo W, et al: Cyclins and cyclindependent kinases: Comparative study of hepatocellular carcinoma versus cirrhosis. Hepatology 37: 534-543, 2003.

29. Liu B, Fan Z, Edgerton SM, Deng XS, Alimova IN, Lind SE and Thor AD: Metformin induces unique biological and molecular responses in triple negative breast cancer cells. Cell Cycle 8: 2031-2040, 2009

30. Han S, Kim HY, Park K, Lee MS, Kim HJ and Kim YD: Expression of p27Kipl and cyclin D1 proteins is inversely correlated and is associated with poor clinical outcome in human gastric cancer. J Surg Oncol 71: 147-154, 1999.

31. Aoyagi K, Koufuji K, Yano S, Murakami N, Terasaki Y, Yamasaki Y, Takeda J, Tanaka M and Shirouzu K: Immunohistochemical study on the expression of cyclin D1 and E in gastric cancer. Kurume Med J 47: 199-203, 2000.

32. Vazquez-Martin A, Oliveras-Ferraros C, Cufí S, MartinCastillo B and Menendez JA: Metformin activates an ataxia telangiectasia mutated (ATM)/Chk2-regulated DNA damagelike response. Cell Cycle 10: 1499-1501, 2011.

33. Wang LW, Li ZS, Zou DW, Jin ZD, Gao J and Xu GM: Metformin induces apoptosis of pancreatic cancer cells. World J Gastroenterol 14: 7192-7198, 2008.

34. Ren M,Zhong X, Ma CY, Sun Y, Guan QB, Cui B, Guo J, Wang H, Gao L and Zhao JJ: Insulin-like growth factor-1 promotes cell cycle progression via upregulation of cyclin D1 expression through the phosphatidylinositol 3-kinase/nuclear factor-kappaB signaling pathway in FRTL thyroid cells. Acta Pharmacol Sin 30: 113-119, 2009 .

35. Pollak M: Insulin and insulin-like growth factor signalling in neoplasia. Nat Rev Cancer 8: 915-928, 2008.

36. Zeng ZS, Cohen AM, Zhang ZF, Stetler-Stevenson W and Guillem JG: Elevated tissue inhibitor of metalloproteinase 1 RNA in colorectal cancer stroma correlates with lymph node and distant metastases. Clin Cancer Res 1: 899-906, 1995.

37. Mori M, Mimori K, Sadanaga N, Inoue H, Tanaka Y, Mafune K, Ueo $\mathrm{H}$ and Barnard GF: Prognostic impact of tissue inhibitor of matrix metalloproteinase-1 in esophageal carcinoma. Int J Cancer 88: 575-578, 2000.

38. Zhang Y, Liao JM, Zeng SX and Lu H: p53 downregulates Down syndrome-associated DYRK1A through miR-1246. EMBO Rep 12: 811-817, 2011.

39. Takeshita N, Hoshino I, Mori M, et al: Serum microRNA expression profile: miR-1246 as a novel diagnostic and prognostic biomarker for oesophageal squamous cell carcinoma. $\mathrm{Br}$ J Cancer 108: 644-652, 2013.

40. Tanaka M, Oikawa K, Takanashi M, Kudo M, Ohyashiki J, Ohyashiki K and Kuroda M: Down-regulation of miR-92 in human plasma is a novel marker for acute leukemia patients. PLoS One 4: e5532, 2009.

41. Liu H, Zhu L, Liu B, Yang L, Meng X, Zhang W, Ma Y and Xiao H: Genome-wide microRNA profiles identify miR-378 as a serum biomarker for early detection of gastric cancer. Cancer Lett 316: 196-203, 2012 .

42. Carmeliet P: VEGF as a key mediator of angiogenesis in cancer. Oncology 69 (Suppl 3): 4-10, 2005.

43. Chen M, Cai E, Huang J, Yu P and Li K: Prognostic value of vascular endothelial growth factor expression in patients with esophageal cancer: A systematic review and meta-analysis. Cancer Epidemiol Biomarkers Prev 21: 1126-1134, 2012. 